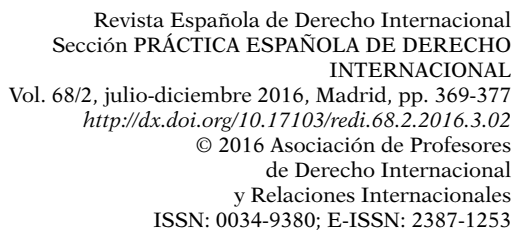

Revista Española de Derecho Internacional Sección PRÁCTICA ESPAÑOLA DE DERECHO INTERNACIONAL Vol. 68/2, julio-diciembre 2016, Madrid, pp. 369-377 http://dx.doi.org/10.17103/redi.68.2.2016.3.02 (C) 2016 Asociación de Profesores de Derecho Internacional y Relaciones Internacionales ISSN: 0034-9380; E-ISSN: 2387-1253

\title{
EL RÉGIMEN DE PROMOCIÓN DE LAS ENERGÍAS RENOVABLES ESPAÑOL PASA SU PRIMER EXAMEN INTERNACIONAL: EL CASO CHARANNE Y CONSTRUCTION INVESTMENTS C. ESPAÑA (FONDO)
}

\author{
Francisco Pascual Vives* \\ Profesor contratado doctor de Derecho internacional público y relaciones internacionales \\ Universidad de Alcalá
}

SUMARIO: 1. INTRODUCCIÓN.-2. LAS ALEGADAS VIOLACIONES DEL TRATADO SOBRE LA CARTA DE LA ENERGÍA.-3. LA OBLIGACIÓN DE PROPORCIONAR UN TRATO JUSTO Y EQUITATIVO.- 4. LA OBLIGACIÓN DE PROPORCIONAR MEDIOS EFICACES PARA EL EJERCICIO DE LOS DERECHOS.-5. LA OBLIGACIÓN DE NO EXPROPIAR INJUSTIFICADA Y DESPROPORCIONADAMENTE.-6. CONSIDERACIONES FINALES.

\section{INTRODUCCIÓN}

En este número de la Revista ya se ha estudiado la parte sobre jurisdicción y admisibilidad del laudo dictado el 21 de enero de 2016 por un tribunal arbitral del Instituto de Arbitraje de la Cámara de Comercio de Estocolmo (CCE) en el caso Charanne y Construction Investments $c$. España (caso CCE núm. 062/2012). En las próximas líneas se examina la parte del laudo que se ocupó de resolver el fondo de la controversia, resaltando algunos aspectos jurídicos que pueden resultar de interés para la interpretación del Tratado sobre la Carta de la Energía (TCE) ${ }^{1}$.

\section{LAS ALEGADAS VIOLACIONES DEL TRATADO SOBRE LA CARTA DE LA ENERGÍA}

Las empresas demandantes alegaron la violación de tres obligaciones internacionales contenidas en el TCE, a saber: la obligación de proporcionar

\footnotetext{
* Este trabajo ha sido realizado en el marco de las actividades de investigación desarrolladas como miembro del proyecto «La Unión Europea ante los Estados fracasados de su vecindario: retos y respuestas desde el Derecho internacional» (Ref. DER2015-63498-C2-1-P MINECO/FEDER).

${ }_{1} B O E$ núm. 117, de 17 de mayo de 1995, y corrección de errores en $B O E$ núm. 167, de 14 de julio de 1995.
} 
un trato justo y equitativo (art. 10.1), la obligación de proporcionar medios eficaces para el ejercicio de los derechos (art. 10.12) y la obligación de no expropiar injustificada y desproporcionadamente (art. 13).

Estas obligaciones se entendieron vulneradas al promulgarse el Real Decreto 1565/2010, de 19 de noviembre, por el que se regulan y modifican determinados aspectos relativos a la actividad de producción de energía eléctrica en régimen especial ${ }^{2}$, el Real Decreto 1614/2010, de 7 de diciembre, por el que se regulan y modifican determinados aspectos relativos a la actividad de producción de energía eléctrica a partir de tecnologías solar, termoeléctrica y eóli$\mathrm{ca}^{3}$ y el Real Decreto-ley 14/2010, de 23 de diciembre, por el que se establecen medidas urgentes para la corrección del déficit tarifario del sector eléctrico ${ }^{4}$.

Estas «normas de 2010» modificaron sensiblemente el régimen jurídico español de incentivos a la producción de electricidad mediante fuentes de energía renovables, estableciendo límites tanto en el plazo de percepción de las tarifas reguladas inicialmente previsto, como en el número de horas equivalentes de producción. Asimismo, impusieron nuevas obligaciones a los productores de energías renovables, obligándoles a cumplir requisitos técnicos adicionales frente a huecos de tensión y a pagar un peaje de acceso a la red.

El laudo sobre el fondo es favorable a los intereses de España, al no apreciar el órgano arbitral que estas modificaciones contravengan las obligaciones asumidas en el marco del TCE. Conviene advertir que solo parte de la treintena de arbitrajes de inversiones sobre energías renovables hasta ahora iniciados contra España impugnan las «normas de 2010». Otras demandas se centran en la legislación dictada posteriormente que, entre otras normas, incluye el Real Decreto-ley 9/2013, de 12 de julio, por el que se adoptan medidas urgentes para garantizar la estabilidad financiera del sistema eléctrico ${ }^{5}$.

El órgano arbitral hizo hincapié en esta distinción ${ }^{6}$, consciente del eventual valor como precedente del laudo y de que sus razonamientos jurídicos serán utilizados inevitablemente como argumentos de ambiente o atmósfera en sucesivos arbitrajes relacionados con el régimen español de promoción de las energías renovables. A continuación se valora la argumentación ofrecida por el órgano arbitral para cada una de las tres presuntas violaciones del TCE.

\section{LA OBLIGACIÓN DE PROPORCIONAR UN TRATO JUSTO Y EQUITATIVO}

La obligación de proporcionar un trato justo y equitativo constituye, por dos razones, el aspecto más discutido en este arbitraje. En primer lugar,

${ }^{2}$ BOE núm. 283, de 23 de noviembre de 2010.

3 BOE núm. 298, de 8 de diciembre de 2010.

${ }^{4}$ BOE núm. 312, de 24 de diciembre de 2010.

5 BOE núm. 167, de 13 de julio de 2013.

6 Charanne y Construction Investments c. España (caso CCE núm. 062/2012, Laudo de 21 de enero de 2016, párrs. 452 y 542). 
por el carácter amplio y complejo con el que ha sido concebida en el art. 10.1 del TCE, como ya ha puesto de relieve algún órgano arbitral llamado a interpretar este tratado internacional ${ }^{7}$. Y, en segundo lugar, al no haberse expropiado directamente la inversión (en todo caso, como se expone en el apartado quinto, se discutió su expropiación indirecta), la conducta controvertida del Estado encajaría mejor en este supuesto, que se centra en el tratamiento proporcionado al inversor ${ }^{8}$.

Las demandantes argumentaron que se había violado esta obligación alegando, primero, que la alteración del marco regulatorio de promoción de las energías renovables en España había generado inestabilidad jurídica, suponía una vulneración de sus legítimas expectativas y constituía una medida desproporcionada y contraria al interés público. Y, segundo, que las citadas medidas habían desplegado efectos retroactivos sobre derechos adquiridos anteriormente.

En cuanto al impacto que la inestabilidad del marco regulatorio produjo en las legítimas expectativas de los inversores, de entrada, el órgano arbitral señaló que al haber las demandantes restringido el objeto de la controversia únicamente a las «normas de 2010», no le resultaba posible realizar un análisis de conjunto donde apreciar la alegada «inestabilidad» del marco regulatorio ${ }^{9}$. Hecha esta precisión, pasó a examinar el argumento de la violación de las legítimas expectativas.

Para resolver este expediente analizó si España había proporcionado a los inversores «compromisos específicos» de mantener el marco regulatorio existente cuando realizaron su inversión. Solo en este supuesto, una ulterior modificación de aquel marco regulatorio podría violentar las expectativas legítimas creadas. A juicio de la mayoría tribunal ${ }^{10}$ :

7 Plama c. Bulgaria (caso CIADI núm. ARB/03/24, Laudo de 27 de agosto de 2008, párr. 163).

8 LóPEz Escudero, M., «Arbitrajes de inversiones contra España por los recortes en los incentivos a la generación eléctrica mediante energías renovables», en MARTín Y PÉREz DE NANCLARES, J. (dir.), España y la práctica del Derecho Internacional. LXXV Aniversario de la Asesoría Jurídica Internacional, Madrid, Escuela Diplomática, 2014, pp. 223-265, pp. 261-265.

9 Charanne y Construction Investments c. España (caso CCE núm. 062/2012, Laudo de 21 de enero de 2016, párrs. 483-484).

10 Sobre esta alegación, en particular, el árbitro Guido Santiago Tawil se separó de la opinión de la mayoría y, amparándose entre otros argumentos en la decisión adoptada por un órgano arbitral fuera del contexto del TCE en Total S. A. c. Argentina (caso CIADI núm. ARB/04/1, Laudo sobre responsabilidad de 27 de diciembre de 2010, párrs. 119-121), firmó una opinión disidente afirmando que: «La generación de expectativas legítimas en un inversor no se encuentra limitada únicamente a la existencia de un "compromiso específico" — sea de naturaleza contractual o fundado en declaraciones o condiciones específicas otorgadas por el Estado receptor- sino que ella puede también derivar o fundarse en el ordenamiento jurídico vigente al momento de realizarse la inversión. En el caso en examen, el esquema normativo en régimen especial puesto en funcionamiento por el Reino de España [...] fijando un "Feed in tariff" [...] fijó con una vigencia temporal —como mínimo- a 25 años y que se declaraba no alcanzado por futuras revisiones tarifarias, sumado a otros documentos emitidos contemporáneamente por el Gobierno español —que si bien no tenían virtualidad por sí solos para generar expectativas legítimas sirven para interpretar el contexto y la finalidad de las medidas regulatorias-, aparecen como determinantes, a mi juicio, para que las Demandantes decidieran realizar la inversión en plantas fotovoltaicas». 
«Las normas en discusión no pierden, por su alcance específico, la naturaleza general que caracteriza cualquier medida legislativa o reglamentaria. Convertir una norma reglamentaria por el carácter limitado de las personas que pueden estar sujeta a la misma [...] en un compromiso específico tomado por el Estado hacia cada uno de dichos sujetos, constituiría una limitación excesiva a la capacidad de los Estados de regular la economía en función del interés general» ${ }^{11}$.

Esta conclusión, que es respetuosa con el poder regulatorio del Estado y enmarca las legítimas expectativas en el contexto de las cláusulas de estabilización o compromisos similares, ha sido mantenida en otros arbitrajes relacionados con la aplicación del TCE al sector de la producción y distribución de energía eléctrica ${ }^{12}$.

Al no existir un compromiso específico sobre el que fundamentar una expectativa legítima, el órgano arbitral ponderó si la misma podría deducirse del conjunto del ordenamiento jurídico vigente en el momento de realizar la inversión. En este punto, siguiendo lo establecido anteriormente por otros órganos arbitrales ${ }^{13}$, afirmó que:

«Admitir la existencia de semejante expectativa sería, en efecto, equivalente a congelar el marco regulatorio aplicable [...]. En la práctica la situación sería equivalente a la resultante de la firma por el Estado de un acuerdo de estabilización» ${ }^{14}$.

La anterior afirmación viene a reforzar una incipiente tendencia en el Derecho internacional económico por reconocer a los Estados cierto margen de discreción en el ejercicio de su poder regulatorio sobre determinados sectores de la economía. Una posición que, por ejemplo, la Unión Europea (UE) está defendiendo en las negociaciones que viene manteniendo con varios Estados con vistas a la celebración de acuerdos internacionales de comercio y protección de las inversiones.

Además, otro aspecto examinado por el tribunal para determinar la inexistencia de una expectativa legítima fue la conducta de los inversores, esto es, valoró si al establecer su inversión las demandantes habían realizado un análisis diligente del marco jurídico, llegando a la conclusión de que:

«Para ser violatorias de las expectativas legítimas del inversor, las medidas regulatorias no deben haber sido razonablemente previsibles en el momento de la inversión. [...] (E)n el presente caso las Demandantes hubieran podido prever fácilmente la posibilidad de ajustes en el marco normativo como los que introdujeron las normas de 2010 (porque la) ley española [...] dejaba claramente abierta la posibilidad de que se modifique el sistema de retribución aplicable a la energía fotovoltaica» ${ }^{15}$.

11 Charanne y Construction Investments c. España (caso CCE núm. 062/2012, Laudo de 21 de enero de 2016, párr. 493).

12 AES Summit y AES-Tisza c. Hungría (caso CIADI núm. ARB/07/22, Laudo de 23 de septiembre de 2010, párrs. 9.3.25-9.3.26).

13 Electrabel c. Hungría (caso CIADI núm. ARB/07/19, Decisión de 30 de noviembre de 2012, Parte VII, p. 21, párr. 7.77).

${ }_{14}$ Charanne y Construction Investments c. España (caso CCE núm. 062/2012, Laudo de 21 de enero de 2016, párr. 503).

15 Ibid., párr. 505. 
En efecto, el análisis de las legítimas expectativas es una operación teórica compleja que no solo conlleva un examen de la conducta estatal, sino también implica una apreciación de la conducta de los particulares ${ }^{16}$.

Con relación a la violación del estándar del trato justo y equitativo, por otra parte, el órgano arbitral analizó si las modificaciones normativas controvertidas podían considerarse como irracionales, desproporcionadas o contrarias al interés público, entre otras razones, al imponer límites a la percepción de incentivos a la producción de energía renovable ${ }^{17}$.

El tribunal rechazó que estas medidas fuesen desproporcionadas o irracionales porque se había probado durante el procedimiento que la vida útil de las instalaciones fotovoltaicas rondaba los treinta años e incluso la mayoría de contratos de arrendamiento de los terrenos donde se habían situado estas instalaciones tenía una duración no superior a ese plazo ${ }^{18}$. Aunque las medidas controvertidas, más restrictivas, pudieran perjudicar los intereses económicos de los inversores, señaló el tribunal que «han sido adoptadas con base en criterios objetivos y no pueden considerarse como irracionales o arbitrarias» ${ }^{19}$. Tampoco las calificó como contrarias al interés público porque se habían adoptado precisamente para «tratar de limitar el déficit y la evolución del precio» ${ }^{20}$ de la electricidad pagado por los consumidores españoles.

En cuanto al carácter retroactivo y la afectación de los derechos adquiridos, el tribunal señaló que esta pretensión:

«No es más que una formulación diferente del argumento según el cual el Estado no tenía la posibilidad de alterar de manera alguna el marco regulatorio del cual se beneficiaban las plantas de las Demandantes. [...] (L)a obligación de otorgar un trato justo y equitativo no implica que el marco regulatorio deba mantenerse igual para todas las plantas elegibles a lo largo de su vida útil. Semejante postura llevaría, en efecto, a congelar el marco regulatorio, limitando cualquier cambio de la regulación a nuevas plantas de generación que se instalaran con posterioridad» ${ }^{21}$.

Las anteriores consideraciones llevaron al órgano arbitral a concluir que no se había vulnerado la obligación de conceder un trato justo y equitativo.

\section{LA OBLIGACIÓN DE PROPORCIONAR MEDIOS EFICACES PARA EL EJERCICIO DE LOS DERECHOS}

Por lo que se refiere a la obligación de proporcionar medios eficaces para el ejercicio de los derechos, las demandantes entendieron que al utilizar el

16 Jiménez Piernas, C. y Pascual Vives, F., «La tutela judicial del principio de protección de la confianza legítima en el Derecho de la Unión Europea», en VV.AA., Riesgo regulatorio en las energías renovables, Pamplona, Aranzadi, 2015, pp. 73-162.

17 Charanne y Construction Investments c. España (caso CCE núm. 062/2012, Laudo de 21 de enero de 2016, párr. 514).

18 Ibid., párr. 527.

19 Ibid., párr. 534.

20 Ibid., párr. 536.

21 Ibid., párr. 546. 
Real Decreto-ley 14/2010 para introducir los cambios normativos, el Estado les privaba de la posibilidad de atacar esta norma en el orden contenciosoadministrativo $^{22}$.

Si bien es cierto que este tipo de normas no pueden recurrirse ante este orden jurisdiccional, no lo es menos que sí pueden ser impugnadas ante los tribunales españoles bien planteando una acción de responsabilidad patrimonial contra el Estado, bien interponiendo una cuestión de inconstitucionalidad.

En cualquier caso, el órgano arbitral concibió la obligación contenida en el art. 10.12 del TCE bajo la óptica del principio de subsidiariedad, es decir, cada Estado puede establecer el sistema de recursos judiciales que considere oportuno. La obligación enunciada por el TCE no es vulnerada mientras este sistema funcione de manera efectiva ${ }^{23}$. Así las cosas, concluyó el tribunal que las vías de recurso previstas en la legislación española:

«Son suficientes para cumplir con la obligación de proporcionar medios eficaces [...] el estándar de medios eficaces en derecho internacional no puede llegar a dictar al Estado las modalidades precisas de organización de su sistema de recursos, obligando por ejemplo al Estado a disponer de un sistema de control directo de la constitucionalidad de sus actos de naturaleza legislativa ${ }^{24}$.

A la luz de lo anterior, tampoco apreció el órgano arbitral una violación del TCE en lo que se refiere a esta obligación internacional.

\section{LA OBLIGACIÓN DE NO EXPROPIAR INJUSTIFICADA Y DESPROPORCIONADAMENTE}

En lo tocante a la obligación de no expropiar injustificada y desproporcionadamente, la reclamación de las demandantes se asentó en dos aspectos

22 Ibid., párrs. 309-312.

23 Ibid., párr. 470. En este contexto, otro órgano arbitral llamado a resolver un arbitraje de inversiones relacionado con la aplicación del art. 10.12 del TCE ya había señalado con relación al criterio de la efectividad que "(b)earing in mind the context and the object and purpose of the ECT, the Tribunal considers that "effective" is a systematic, comparative, progressive and practical standard. It is systematic in that the State must provide an effective framework or system for the enforcement of rights, but does not offer guarantees in individual cases. Individual failures might be evidence of systematic inadequacies, but are not themselves a breach of Article 10(12). It is comparative in that compliance with international standards indicates that imperfections in the law might result from the complexities of the subject matter rather than the inadequacies of the legislation. It is progressive in the sense that legislation ages and needs to be modernized and adapted from time to time, and results might not be immediate. Where a State is taking the appropriate steps to identify and address deficiencies in its legislation - in other words improvement is in progress - then the progress should be recognized in assessing effectiveness. Finally, it is a practical standard in that some areas of law, or the application of legislation in certain circumstances, raise particular difficulties which should not be ignored in assessing effectiveness »: véase Limited Liability Company Amto c. Ucrania (caso CCE núm. 080/2005, Laudo final de 26 de marzo de 2008, párr. 88).

${ }^{24}$ Charanne y Construction Investments c. España (caso CCE núm. 062/2012, Laudo de 21 de enero de 2016, párr. 472). 
complementarios. Primero, el TCE ofrece un concepto de inversión amplio donde caben no solo los activos o acciones, sino también su valor económico y los rendimientos derivados de los mismos ${ }^{25}$. Y, segundo, el art. 13.1 del TCE regula las expropiaciones directas e indirectas ${ }^{26}$.

Es precisamente este segundo tipo de expropiación el que alegaron las demandantes, pues aunque mantuvieron la titularidad sobre sus activos, las «normas de 2010» impactaron negativamente en los rendimientos derivados de los mismos. La afectación admitida por las demandantes supuso una reducción de la rentabilidad no superior al 10 por 100 respecto a los márgenes que venían disfrutando ${ }^{27}$. En otras palabras, si bien es cierto que los rendimientos derivados de las plantas fotovoltaicas quedaron afectados, las propias demandantes reconocieron que su inversión siguió siendo rentable, aunque menos de lo que inicialmente habían previsto.

Conforme a estos hechos y tras matizar que el objeto de la inversión efectuada por las demandantes fueron acciones y no rendimientos ${ }^{28}$, el tribunal ponderó si las medidas controvertidas podían considerarse como una expropiación indirecta sirviéndose del estándar invocado por otros órganos arbitrales en el contexto del TCE y del Derecho internacional económico ${ }^{29}$. Una expropiación indirecta puede tener su origen tanto en una pérdida del control sobre la inversión, como en una pérdida del valor de las acciones. En este último caso, debe producirse una afectación sustancial del derecho, esto es, la pérdida de valor «tiene que ser de tal magnitud que equivalga a una privación de propiedad ${ }^{30}$. En el supuesto que nos ocupa, el órgano arbitral concluyó que no existía expropiación indirecta porque:

«Una simple disminución del valor de las acciones objeto de la inversión no puede [...] caracterizar una expropiación indirecta, a menos que la pérdida sea tal que se pueda considerar equivalente a una privación de propiedad ${ }^{31}$.

Por último, en el capítulo relativo a la imposición de las costas procesales y los gastos de representación legal, conforme a lo establecido en el art. 44 del Reglamento de arbitraje del Instituto de Arbitraje de la CCE, el tribunal estimó que se debían reembolsar a la demandada las cantidades que había anticipado en concepto de costos del arbitraje (134.604,14 euros y 5.155 dólares estadounidenses), así como una parte de sus propios gastos razonables (1.176.181,31 euros), en tanto que había resultado exitosa en la fase del fondo, pero no en la de jurisdicción.

25 Ibid., párr. 278

26 Ibid., párr. 279.

27 Ibid., párr. 284.

28 Ibid., párr. 459.

${ }_{29}$ Mamidoil c. Albania (caso CIADI núm. ARB/11/24, Laudo de 30 de marzo de 2015, párrs. 568571).

30 Charanne y Construction Investments c. España (caso CCE núm. 062/2012, Laudo de 21 de enero de 2016, párr. 464).

31 Ibid., párr. 465. 


\section{CONSIDERACIONES FINALES}

Para concluir, conviene realizar tres reflexiones de carácter más general que sobrepasan los límites del comentario realizado en las anteriores líneas. En primer lugar, interesa comparar la argumentación realizada por el órgano arbitral para ponderar la vulneración de las legítimas expectativas al calor del TCE con la desarrollada por algunos tribunales españoles (Tribunal Supremo y Tribunal Constitucional) que también se han pronunciado sobre esta cuestión en los múltiples litigios interpuestos por inversores españoles contra el régimen de fomento de las energías renovables. Aunque en ocasiones se critica, con razón, la argumentación poco persuasiva que desarrollan algunos tribunales internacionales cuando adoptan decisiones muy deferentes con los Estados (por ejemplo, cuando el Tribunal Europeo de Derechos Humanos invoca la noción del margen de apreciación nacional para concluir que no existe responsabilidad internacional del Estado), en este caso se aprecia una diferencia significativa entre la argumentación hilvanada por el órgano arbitral y la de los citados tribunales españoles. Como ha señalado un magistrado de nuestro Tribunal Constitucional en su voto particular a la Sentencia 270/2015, de 17 de diciembre ${ }^{32}$, a propósito de un recurso de inconstitucionalidad interpuesto contra el Real Decretoley 9/2013: «Hubiera sido necesario un esfuerzo argumental muy superior al desarrollado en la opinión mayoritaria en la que se sustenta (esta) sentencia».

En segundo lugar, cabe felicitarse de la decisión tomada por el Ministerio de Industria, Energía y Turismo de publicar en su sitio web una nota de prensa que incluía tanto el laudo como la opinión disidente, solo cinco días después de haberse dictado. Este ejercicio de transparencia contrasta notoriamente con la absoluta confidencialidad que hasta ahora había caracterizado la conducta española en los arbitrajes de inversiones relacionados con las energías renovables. Cabe esperar que esta decisión ministerial no resulte un comportamiento oportunista y siente un precedente en materia de buenas prácticas relacionadas con la transparencia en el arbitraje de inversiones. La UE está apostando decididamente por impulsar este expediente en las negociaciones que mantiene con varios Estados mientras hace efectiva la faceta externa de su competencia sobre protección de las inversiones extranjeras. Por mera coherencia en el ejercicio de la acción exterior, sus Estados miembros también deberían cultivar esas buenas prácticas.

Y en tercer y último lugar, habrá que estar pendientes de las decisiones que adopten los órganos arbitrales llamados a confrontar con el TCE los cambios en el régimen de promoción de las renovables introducidos por España tras el año 2010. En el caso, todavía hipotético, de que estos órganos resolvieran a favor de los inversores extranjeros, ¿podría la Comisión Europea alegar que el pago de la eventual indemnización impuesta en el laudo arbitral

32 BOE núm. 19, de 22 de enero de 2016. 
constituye una ayuda de Estado contraria al Derecho de la UE? ${ }^{33}$. Al Reino de España todavía le quedan pendientes duras reválidas en sede internacional, comunitaria e interna ${ }^{34}$ a propósito del régimen de promoción de las energías renovables.

\footnotetext{
33 Este es el caso, por ejemplo, del arbitraje de inversiones iniciado contra Rumania por unos inversores de origen sueco [Ioan Micula, Viorel Micula y otros c. Rumania (caso CIADI núm. ARB/05/20, Laudo de 11 de diciembre de 2013)]. Para un comentario de los problemas jurídicos que plantea este caso: véase la comunicación de PIERnAs LóPEz, J. J., «Entre la espada y la pared: Estados miembros de la Unión Europea y arbitraje internacional. Repercusiones del caso Micula para la interrelación de España y la UE en la esfera internacional», realizada en el contexto de las XXVI Jornadas ordinarias de la Asociación Española de Profesores de Derecho Internacional y Relaciones Internacionales (Sevilla, octubre de 2015).

34 Desde la perspectiva del ordenamiento jurídico español, importa reflexionar sobre los mecanismos de ejecución de los laudos internacionales y/o extranjeros: véase «Crónica sobre la solución de controversias en materia de inversiones extranjeras (enero-diciembre 2015)», REEI, núm. 31, 2016, apartado VII.3.
} 